\title{
Dossiê
}

REsumo
Neste artigo propõe-se uma
análise crítica dos modos como
as dificuldades de aprendiragem
foram abordadas pela ciência
psiquiátrica quando de seu
surgimento como um problema
social. A despeito da diversida-
de de teorias sobre a criança e
seu desenvolvimentoproduzidas
na primeira metade do século
XX, identificamos a predo-
minância de uma abordagem
funcionalista, tendência evidente
tanto nos esforços em busca
de uma causalidade orgânica
quanto na consideração de uma
"causalidade psíquica" nas
justificativas das dificuldades
de aprendiragem. Em ambos os
casos ficapatente o silenciamen-
to das crianças, tratadas como
mero objeto das mais diversas
especulaçôes científicas.
Descritores: dificuldades
de aprendizagem; ciência
psiquiátrica; crianças.

\section{AS DIFICULDADES DE APRENDIZAGEM E A CIÊNCIA PSIQUIÁTRICA: UMA LEITURA CRÍTICA}

Maria Alice Moreira Lima

A educação como prática humanizadora não tem limite de idade, e é possível supor que, desde o início, as tentativas de educar já viessem acompanhadas de algumas dificuldades, tanto para quem ensina como para quem aprende. Contudo, constatamos que as dificuldades nem sempre foram tratadas da mesma maneira, cabendo aos discursos estabelecidos em cada época e lugar determinar a maneira como se nomeia o que não funciona bem na vida de todos e de cada um.

Assim, será a nova concepção de ciência que se inaugura no século XVII a responsável pela abordagem das dificuldades de aprendizagem que irão se constituir em um desafio social significativo, a 
partir da generalização da educação escolarizada obrigatória, ciência que constata a "caducidade" do saber acumulado até então, decorrente da descoberta de um real sempre a exigir novas elaborações e revisões das anteriores. Como bem expressa Marie-Jean Sauret (2003): "Diríamos, hoje, que a ciência moderna aparece com a descoberta do real como o que põe em cheque o saber e provoca uma nova elaboração. Só que, daí em diante, o cientista sabe que todo saber está à mercê do real" (p. 90), real como o que se impôs a Galileu ao constatar os movimentos terrestres, pondo abaixo os saberes até então estabelecidos, convocando novas elaborações. Decorre dessa posição que os esforços da ciência encontrarão sempre um ponto de basta, um impossível que se impõe como inerente à sua capacidade de teorização. Entendemos que a ciência, enquanto um discurso autorizado a abordar questões de interesse social, deverá ser tomada como também possuindo um real, um limite.

A despeito dessa constatação, a ciência moderna, através das vicissitudes de seu projeto de constituir-se como forma segura de produção de conhecimento, tratará seus objetos, muitas vezes, ignorando esse ponto de basta onde um não saber se aloja. Essa será, a nosso ver, a tônica da abordagem das dificuldades de aprendizagem quando estas adquirem o status de um problema social, a partir de meados do século XIX. Através desse processo de elaboração de saber, veremos como crianças com dificuldades para aprender são reduzidas a um diagnóstico que sela para as mesmas um único destino social. Ao traçarmos o percurso que se inaugura

442 Estilos clin., São Paulo, v. 20, n. 3, set./dez. 2015, 441-458. 
com o estabelecimento da escolarização obrigatória na Europa e o consequente tratamento dado às dificuldades das crianças pela ciência psiquiátrica, constatamos um processo de segregação e silenciamento dos sujeitos que ainda não encontrou seu fim. Reduzidos a objetos de um determinado modo de se produzir ciência, essas crianças, por nós concebidas como sujeitos capazes de escrever a própria história, continuam a ser estigmatizadas e silenciadas pelos diagnósticos que se impõem, como um destino, sob suas cabeças. Vejamos então como esse processo, no que se refere especificamente às dificuldades de aprendizagem, teve seu início. Para tanto, realizamos uma investigação bibliográfica em que procuramos identificar alguns dos modos como esse fenômeno, que ainda hoje nos coloca a trabalho, foi abordado pela ciência.

\section{Escola para todos como dever do Estado}

A exploração do campo da educação, concebida como uma prática atrelada à própria condição humana, exige que estabeleçamos critérios de corte a fim de viabilizar uma análise organizada de seu percurso ao longo da história. Para nossos objetivos, será de extrema importância a compreensão do momento denominado por Esteve (2004) de "a segunda revolução educacional", quando se dissemina a obrigatoriedade de educação para todas as crianças, organizada e oferecida pelo Estado. Iniciado, portanto, ao final do século XVIII, o processo de estatização e universalização da educação irá se desenrolar nos dois séculos seguintes e será determinante, entre outros fatos significativos, para o encontro entre a ciência psiquiátrica e as dificuldades de aprendizagem, compreendidas como um produto indesejável do processo de escolarização.

Nesse contexto, que abrange as revoluções liberais que se estendem do século XVIII a meados do século XIX, destaca-se o processo de escolarização na França, 
que será marcado profundamente pela intervenção de Jules Ferry (1832-1893). Ferry, então ministro da instrução pública durante a terceira república, recupera e reconhece o relatório do Marquês de Condorcet (1743-1794), um dos líderes ideológicos da Revolução Francesa, que propunha uma escola pública universal, laica, gratuita, para ambos os sexos e em todos os seus níveis.

No mandato de Ferry são promulgadas as leis que garantem o ensino primário gratuito (lei de 16 de junho de 1881) e obrigatório (lei de 28 de março de 1882) na França. O projeto educacional francês, estabelecido sob as bases universalizantes e democráticas formuladas por Condorcet, torna-se, segundo a historiadora Carlota Boto (2003), "uma referência transnacional, pautando, como modelo, projetos e parâmetros reformadores da instrução pública nos mais variados países da Europa (e inclusive na América Latina, particularmente no Brasil)" (p. 742).

A obrigatoriedade da oferta de ensino ampliará significativamente o contingente de crianças na escola, o que resultará no aparecimento de um número significativo de crianças com dificuldades no processo de escolarização. As dificuldades de aprendizagem adquirem, nesse contexto, uma visibilidade jamais encontrada, exigindo um esforço também amplo de compreensão e abordagem desse fenômeno que, a partir de então, se apresenta como uma questão social de significativa importância. É notável o investimento do governo francês nesses casos, chegando a ser promulgada uma lei (1904) determinando a aplicação de exames médicos, pedagógicos e psicológicos às crianças com dificuldades escolares, tarefa, delegada a Alfred Binet (1857-1911) e Théodore Simon (1872-1961), que descreveremos posteriormente.

Ao mesmo tempo em que se desenvolve, na França, um modelo de educação pública que acaba por produzir novas demandas de identificação e tratamento de seus produtos, é também lá que tem início uma verdadeira revolução no âmbito do saber psiquiátrico. Lembremos que a história da psiquiatria encontra-se profundamente marcada pelos trabalhos dos psiquiatras franceses do final do século XVIII e início do século XIX, sendo Phillipe Pinel (1745-1826) considerado, por muitos, o pai da psiquiatria moderna. Por sua pena introduzem-se, no campo da psiquiatria, os princípios de uma orientação "verdadeiramente científica" (Bercherie, 1989, p. 31), decorrente da observação sistemática dos fenômenos que constituem a realidade. Será no campo da ciência psiquiátrica assim concebida que encontraremos os desdobramentos da abordagem às crianças identificadas como possuindo dificuldades para aprender.

O processo de valorização do cidadão livre e as bases para sua concretização, das quais o novo modelo educacional constituía uma 
parte fundamental, colocaram em evidência a distinção entre adulto e criança. Distinção que, segundo Ariès (1981), se reafirmaria sobre as transformações da concepção de infância que, desde o século XVIII, já anunciavam uma visão da criança como um ser que exigiria uma formação, um tratamento cuidadoso a fim de prepará-la para a vida adulta.

Consonante com o contexto cultural da época, as referências utilizadas para esse processo de formação da criança serão tomadas no âmbito da ciência moderna, cuja abordagem, acreditava-se, viria desmistificar os saberes até então existentes. Assim, afirma Marie-Jean Sauret (1998), "a criança é oferecida pés e mãos atados aos especialistas da ciência e da educação" (p. 13). Essa posição é reforçada por Cirino (2001) ao lembrar que a emergência do "sentimento de infância", que encontra-se associada a uma concepção de família como um núcleo restrito determinado por sentimentos íntimos, é o que favorece que a criança seja pensada como o "homem de amanhã". Assim destacada, a criança virá a ser "recortada como objeto de teorização e de práticas educacionais, higiênicas e científicas" (Cirino, 2001, p. 22).

Desse modo, tem início um longo processo que se estende até os dias atuais e se traduz em um esforço permanente em abordar, com os recursos científicos disponíveis, o que diz respeito à criança e, especialmente, o que extrapola o universo supostamente estável dos fenômenos educacionais estabelecido pelo discurso dominante.

\section{Idiotia, primeira denominação das dificuldades de aprendizagem no campo da psiquiatria}

Apesar da prevalente concepção da criança como distinta do adulto, reforçada pela nova ordem escolar, no âmbito da psiquiatria clássica as demandas referentes às dificuldades escolares das crianças serão acolhidas, até a década de 1930, a partir das referências clínicas e nosológicas estabelecidas para o adulto.

O recente processo de escolarização obrigatória na França encontrará, contudo, a clínica psiquiátrica em plena discussão sobre a noção de retardamento mental proposta por Esquirol (1772-1840) e antes denominada idiotia. Nesse contexto não se admite a loucura propriamente dita na criança, pois entende-se que, nela, as afecções poderiam 
produzir interrupções no desenvolvimento, mas não se instalariam de maneira definitiva. Consequentemente, nesse período, que compreende as sete primeiras décadas do século XIX, "a loucura da criança é, essencialmente, a idiotia” (Bercherie, 2001, p. 132). A descrição de idiotia proposta por Esquirol irá se mostrar, contudo, bastante útil na nomeação das dificuldades identificadas nas crianças escolarizadas. Segundo o que nos informa Bercherie (2001), para Esquirol "o idiota é aquele que não pode adquirir os conhecimentos, que normalmente se adquire pela educação" (p. 131). Além disso, entendia ser a idiotia decorrente de uma afecção essencialmente orgânica, relacionada a vícios de conformação do cérebro, portanto, incurável. Diferentemente, para Séguin (1812-1880), Voisin (1794-1872) e Delasiauve (18041893), representantes da chamada corrente humanista da psiquiatria, o déficit apresentado pelas crianças era, na maioria dos casos, parcial, podendo ser revertido através de uma educação especial. Com essa posição ficaram conhecidos como "educadores de idiotas", grupo a que se somava Jean Itard (1774-1838), tornado célebre por sua tentativa de educar o pequeno Victor, conhecido como o Selvagem de Aveyron. Édouard Séguin, por sua vez, será o precursor da "educação especial", uma tradição bastante fecunda, de acordo com Bercherie (2001). Destacam-se também, nesse período, outras iniciativas na mesma direção, como a introdução das "classes especiais" no ensino público, voltadas ao aprendizado de crianças deficientes, por Édouard Claparède (1873-1940), neurologista suíço e psicólogo do desenvolvimento infantil.

Esse será o quadro predominante no século XIX. Em termos de diagnóstico, as dificuldades de aprendizagem eram atribuídas à idiotia, embora, como assinala Santiago (2005), àqueles envolvidos com a educação dos chamados idiotas faltasse clareza quanto ao potencial de inteligência associado às diversas formas de idiotia. Coloca-se, dessa forma, o problema de delimitação entre o normal e patológico. Será necessário, então, estabelecer formas de aferição do potencial intelectual 
das crianças, demanda que traduz perfeitamente o ambiente científico do final do século XIX, quando prevalecia a crença nos dispositivos de objetivação dos fenômenos, metodologia proveniente das pesquisas no âmbito das ciências naturais. Por conseguinte, para atender às demandas dessa "psiquiatria pedagógica experimental promovida pela corrente humanista" (Santiago, 2005, p. 59), serão desenvolvidas, por Binet e Simon, as escalas métricas para a medida do desenvolvimento da inteligência nas crianças.

\section{A abordagem psicométrica das dificuldades de aprendizagem}

O primeiro decênio do século XX será marcado pela atenção maior dispensada à criança e, especialmente, à sua instrução. Nesse contexto ganha destaque a demanda por uma avaliação mais "precisa" da inteligência, impulsionada, principalmente, pelos desafios gerados pelas crianças com dificuldades no processo de escolarização. Vejamos, então, o que representou a elaboração das escalas de Binet e Simon para a abordagem das dificuldades de aprendizagem.

De acordo com Simon (1929), o desenvolvimento das escalas se deu como resposta às dúvidas geradas a partir das pesquisas de Binet sobre as correlações entre o volume da cabeça e o grau de inteligência. Segundo Simon, Binet mostrava-se insatisfeito quanto à impossibilidade de se precisar tais correlações. A aferição do volume da cabeça era uma metodologia comum, também praticada por Simon nas crianças da Colônia de Vaucluse, onde trabalhava. Estas eram diagnosticadas como idiotas, imbecis e débeis mentais, contudo, Simon constata que "nas minúcias, essas classificações ficavam de tal modo envolvidas em sombra de dúvidas, de incertezas, de contradições, que uma revisão se impunha" (Binet \& Simon, 1929, p. 12). As escalas para a medida do desenvolvimento da inteligência foram elaboradas com a intenção de precisar melhor as diferenças, no que toca à inteligência, entre as patologias já identificadas pela psiquiatria da época. Os estudos com esses indivíduos, afirma Simon (1905), deram início aos interrogatórios metódicos que conduziram à primeira escala métrica da inteligência, em 1905.

O critério relacionado à inteligência será predominante nas avaliações realizadas nas crianças no final do século XIX e início 
do século XX e os resultados encontrados relacionados às clássicas nomenclaturas psiquiátricas. Desse modo, como afirma Santiago (2005), termos como "idiotas", "débeis" e "imbecis", oriundos da psiquiatria clássica, fazem seu ingresso no campo da educação.

Nesse contexto é criada a já mencionada comissão proposta pelo Ministério da Instrução Pública Francês. A tarefa será delegada a Binet e Simon, e terá como objetivo "determinar quais as crianças incapazes de acompanhar seus condiscípulos, por insuficiência de meios intelectuais" (Binet \& Simon, 1929, p. 12-13). Constatam, então, que o desempenho das crianças com problemas escolares, em geral, correspondia ao desempenho de crianças mais novas, quando submetidas às mesmas provas. Desse modo, a relação entre inteligência e idade aparece como um critério de avaliação intelectual. Às denominações já existentes sobre as patologias associadas às crianças acrescenta-se, dessa forma, uma nova concepção, que terá grande aplicação nos meios educacionais, nos tribunais de crian$\operatorname{ças}^{2}$ e nos empreendimentos de caráter eugênico: a idade mental.

As Escalas de Desenvolvimento da Inteligência apresentam-se, então, como um instrumento eficaz e seguro, por seu caráter científico, de classificação das crianças. Para Simon, os testes criados por Alfred Binet, com sua participação, se consolidaram como o "primeiro exemplo de medida direta do valor psicológico dos indivíduos" (Binet \& Simon, 1929, p. 29). Através das afirmações de Simon, fica patente o valor atribuído à inteligência como critério classificatório dos sujeitos em diversos âmbitos da vida social. Contudo, será sobre as crianças escolarizadas, como o próprio autor enfatiza, que recairão os principais efeitos da utilização dessa nova medida.

Mesmo não introduzindo novas nomenclaturas, entendemos que o caráter organizador da abordagem psicométrica favoreceu a consolidação dos diagnósticos já existentes ao colocá-los à prova através de instrumentos validados pelo modelo de ciência hegemônico. Temos, assim, um exemplo de como um diagnóstico ganha força, adquirindo, aos poucos, a aparência de verdade irrefutável.

Paralelamente à crescente utilização das escalas de medida da inteligência dá-se o processo de constituição de uma psiquiatria específica da criança, na qual encontraremos os principais desdobramentos da abordagem psiquiátrica das dificuldades de aprendizagem.

\section{A psiquiatria infantil e o tratamento dado às dificuldades de aprendizagem}

Os primeiros tratados de psiquiatria infantil datam do final do século XIX, mais especificamente no final da 
década de $1980^{3}$, marcados pela tendência em buscar identificar, na criança, ao lado do retardamento, as mesmas síndromes mentais dos adultos. Dessa forma, a psiquiatria infantil, nos primórdios de sua constituição, permaneceria atrelada à psiquiatria do adulto, sem um modelo próprio de pesquisa e abordagem clínica. Os esforços para sua constituição como campo independente, no entanto, prosseguem e se fortalecerão no ano de 1937, cujo marco foi o $1^{\circ}$ Congresso Internacional de Psiquiatria Infantil, realizado em Paris, onde é fundada a Associação Internacional de Psiquiatria Infantil. Tal fato marca a consolidação da psiquiatria infantil e seu desligamento da psiquiatria do adulto e da pediatria.

É preciso, contudo, compreender o que, de fato, determina a diferenciação entre as clínicas psiquiátricas do adulto e da criança. Para Bercherie (2001), a clínica pedopsiquiátrica moderna será constituída a partir dos aportes de uma psicologia da criança e de seu desenvolvimento, o que possibilita a construção de uma nova concepção de infância que possui sua própria ordem de existência e racionalidade, passando a esclarecer o futuro do adulto.

Fortemente influenciada pelas teorias psicológicas, pelas ideias pedagógicas e pela psicanálise, a clínica psiquiátrica infantil se distingue definitivamente da clínica do adulto, que permaneceria orientada pelo paradigma médico. As referências que marcam essa influência serão encontradas nos trabalhos de Anna Freud (18961982), M. Klein (1882-1960) e Winnicott (1896-1971), na criação das escolas de psicanálise, nos estudos de Spitz (1887-1974) sobre o desenvolvimento, em estudos de inspiração etológica ${ }^{4}$ e pluridimensionais. A clínica da criança, recém-organizada segundo essas tendências, proporcionará uma renovação nos diagnósticos sobre as afecções infantis, o que também se refletirá na compreensão acerca das dificuldades de aprendizagem. Destacam-se, nesse contexto, as pesquisas sobre o desenvolvimento infantil que, predominantemente amparadas pelo modelo funcionalista, representados por Dewey (1859-1952), Watson (1878-1958) e Gesell (1880-1961), nortearão os diagnósticos estabelecidos pela psiquiatria infantil que se inaugurava. As correntes funcionalistas, que tinham como paradigma os princípios evolucionistas de Darwin, serviram, segundo Ferreira e Araújo (2009), "não só como estímulo, mas, principalmente, como suporte teórico e metodológico para os estudos sistemáticos sobre o desenvolvimento do psiquismo humano e suas possíveis aplicações no contexto escolar" (p. 10). 
Os desdobramentos das influências dessas pesquisas sobre a criança e seu desenvolvimento para a compreensão das patologias e dificuldades experimentadas nessa etapa inicial da vida serão emblematicamente representados nos manuais de psiquiatria infantil que foram produzidos a seguir. Nesse contexto, merecem destaque o manual de Psiquiatria Infantil de Leo Kanner, psiquiatra austríaco radicado nos EUA, publicado em 1935, e o Manual de Psiquiatria Infantil de Julien de Ajuriaguerra, cuja primeira publicação data de 1970. O primeiro, segundo Bercherie (2001, p. 137), "continua sendo a principal obra de referência" no campo da psiquiatria infantil por sua concepção de conjunto, o que possibilitou a percepção da clínica psiquiátrica da criança como um "todo homogêneo". O manual de Ajuriaguerra, por sua vez, oferece-nos uma rica exposição das patologias mentais infantis, mais especificamente dos problemas relacionados à aprendizagem e educação, já acrescidas das contribuições ao conhecimento do desenvolvimento da criança produzidas ao longo do século XX.

\section{O manual de Kanner}

Leo Kanner concordava com os intelectuais da época que teriam definido o século XX como o "século da criança": momento em que uma série de instituições e movimentos foram criados com a finalidade de atendimento às demandas específicas desse público. A "liberdade vigiada", "as casas de criança e a educação especial" e a constituição das "Clínicas de Orientação Multiprofissionais", contando com o trabalho de psiquiatras, psicólogos e assistentes sociais, são exemplos desses movimentos. Além disso, destaca a inclusão das crianças nos processos terapêuticos, que se dará a partir do quarto decênio do século XX. Tais iniciativas reforçam a importância e relevância das produções científicas sobre a criança produzidas nesse momento.

A elaboração do referido manual, como nos indica seu autor, tentará reunir as contribuições recentes da psicologia para a compreensão do desenvolvimento da criança, que se somarão às descrições da psiquiatria clássica. Entre as referências trabalhadas por Kanner destacam-se os trabalhos de orientação funcionalista e behaviorista (Dewey, 1935; Gesell, 1940; Watson, 1925, citados 
por Kanner, 1971, p. 58) além das contribuições de Piaget ${ }^{5}$ (1928, citado por Kanner, 1971, p. 59) e Binet e Simon (1905, citados por Kanner, 1971, p. 30). O aporte teórico assim organizado será a base para a abordagem das mais diversas questões relacionadas à criança, entre as quais destacaremos as relativas à inteligência, aos problemas da fala e da linguagem e aos problemas escolares, temáticas mais diretamente relacionadas às dificuldades de aprendizagem, objeto principal de nossa análise.

Fica patente, na abordagem da concepção de inteligência, o valor dado por Kanner às contribuições da Psicometria de Binet. Embora considere a inteligência uma função complexa, cujas relações ainda não estão devidamente esclarecidas, no decorrer da obra utilizará os resultados das provas psicométricas como dado importante na descrição das patologias e avaliação dos quadros analisados.

Os problemas associados à fala e à linguagem, tais como mutismo, iniciação demorada da fala, transtornos da articulação, transtornos da fonação e gagueira, serão considerados segundo suas prováveis causas orgânicas, as relações com os diversos níveis de inteligência e a possibilidade de serem efeito das relações que as crianças estabelecem com os adultos ou outras crianças à sua volta. Esse esforço de compreensão encontrará uma série de obstáculos ao se deparar com dificuldades cuja abordagem, através dos três eixos estabelecidos, se mostrará insuficiente. Um exemplo são os chamados "transtornos de compreensão". As incertezas quanto a esses transtornos são enormes e produzem diagnósticos diferenciados e, por vezes, contraditórios. Kanner ilustra essa situação com o caso de uma criança que chegou a receber, de vários especialistas, diagnósticos expressos nas seguintes formas: "Deixe-o, ele já irá falar", "É uma criança mimada”, “Ouve perfeitamente”, "É ‘duro’ de ouvido", “É inteligente", "É débil mental", "Tem a língua um tanto bruta", "Os nervos o entorpecem” (Kanner, 1971, p. 531, tradução nossa) ${ }^{6}$.

Kanner prossegue em seu exame do que chamou problemas escolares. Nesse contexto, dedicará especial atenção à incapacidade para a leitura em crianças que não apresentem qualquer déficit intelectual ou dano orgânico, o que representava um desafio para o saber médico até então adquirido. O tema merece destaque uma vez que, embora já constassem pesquisas que estabeleciam relações entre essa dificuldade e estruturas ou funções orgânicas (Hinshelwood, 1947; Orton, 1925, citados por Kanner, 1971, p. 562), existiam estudos que refutavam a relação entre dominância cerebral e a capacidade de 
ler, nos lembra Kanner. Assim, a incapacidade de ler em algumas crianças, a que damos o nome de dislexia ${ }^{7}$, se apresentava como uma questão para a qual as respostas até então estabelecidas mostravam-se insuficientes.

$\mathrm{O}$ texto de Kanner permite que compreendamos como se situa, nos seus primórdios, a psiquiatria infantil em relação aos problemas relacionados à aprendizagem e à vida escolar. Observamos em seu texto a relativa segurança com que são apresentadas as prováveis causas orgânicas e a utilização dos resultados dos testes de inteligência. É perceptível a influência das ideias psicanalíticas que, segundo Paul Bercherie (2001), terão uma participação importante na clínica psiquiátrica infantil nesse período. Porém, no texto de Kanner, as ideias psicanalíticas não se encontram desenvolvidas e sua utilização é bastante restrita e parcimoniosa, reduzindo-se às menções aos aspectos relacionais da vida das crianças, tanto passados como futuros. Não obstante, ressalta-se a forte presença das ideias funcionalistas, marca da psicologia americana do início do século XX, que concebem o psiquismo como uma função mediadora entre o organismo e o ambiente. A definição de personalidade proposta por Kanner, ao endossar a formulação de Allport (1937), confirma a posição adotada quanto ao funcionamento mental: "A personalidade é a organização dinâmica, dentro do indivíduo, dos sistemas psicofísicos que determinam sua singular adaptação ao ambiente que o rodeia” (Kanner, 1971, p. 107, tradução minha) ${ }^{8}$. Será, contudo, no Manual de Psiquiatria Infantil de Ajuriaguerra, que analisaremos a seguir, que esse modelo funcionalista se apresentará de forma mais contundente.

\section{O manual de Ajuriaguerra}

Julian de Ajuriaguerra (19111993) foi um eminente psiquiatra e professor de origem espanhola. Reconhecido por suas contribuições ao desenvolvimento da psiquiatria, principalmente através de seus trabalhos em Genebra, foi eleito professor do Collège de France em Paris e autor de um dos mais conhecidos tratados de psiquiatria infantil.

A primeira publicação do manual data de 1970, logo, muitos anos depois da publicação do texto de Kanner, em um contexto de rica produção teórica. Assim, Ajuriaguerra introduz as teorias de Piaget, Wallon (1879-1962), Spitz e Klein, anunciando o esforço que fará para contemplar, da maneira mais ampla possível, as contribuições dessas diversas correntes para a compreensão das questões relacionadas à infância. Tal esforço, entretanto, nem sempre resultará em formulações conclusivas, uma vez que as teorias utilizadas, como as pesquisas behavioristas e os estudos interacionistas, invariavelmente apresentavam 
divergências quanto aos fundamentos de processos considerados. Por outro lado, ficará evidente a opção do autor, tal como se verificou em Kanner, por uma abordagem funcionalista dos fenômenos, embora nem sempre colocada de modo explícito.

Na compreensão que nos oferecerá sobre a linguagem, já é sensível a tendência que orienta sua obra. Para Ajuriaguerra, a linguagem depende de uma "dotação de base" orgânica associada a componentes pulsionais ${ }^{9}$ e relacionais. Destacamos aí o fato do "orgânico" aparecer como ponto de partida em relação ao qual os demais processos se desenvolvem. Os distúrbios de linguagem, por sua vez, serão abordados segundo os mesmos critérios, o que produz uma variedade etiológica que dificulta uma definição ou localização precisa dos mesmos. Constatamos, então, desde as elaborações de Kanner, uma dificuldade em precisar as causas de tais distúrbios.

\section{As dislexias}

O tratamento dado às dificuldades de aprendizagem da língua escrita propiciará mais um exemplo das dificuldades em se chegar a uma posição conclusiva. Ajuriaguerra apresentará uma série de estudos que colocam em questão cada um dos fatores até então relacionados como provável causa da incapacidade de leitura, a saber: distúrbios perceptivos, distúrbios de linguagem, distúrbios da organização espaço-temporal, distúrbios de lateralização, distúrbios afetivos e fatores constitucionais, relativos à herança genética. Sem chegar a alguma conclusão, questiona-se se seria mais apropriado falar de dislexias, conforme alguns autores germânicos que distinguiriam então "uma dislexia verbal e auditiva de uma dislexia espacial ou uma dislexia óptica, em relação com imagens visuais deformadas, e uma dislexia acústica, que consiste em surdez para matizes fonéticos" (Ajuriaguerra, 1983, p. 318).

Independentemente dos esforços em ampliar o conjunto de fatores envolvidos, o que parece prevalecer é um confronto entre os que tendem a conceber a dislexia como decorrente de uma desordem cerebral e os que apostam unicamente em fatores sociopedagógicos. Ajuriaguerra tenderá a posicionar-se junto aos que elegem os fatores psicopedagógicos como causa, entendendo ser mais promissor investir na pesquisa dos aspectos pedagógicos associados à aquisição 
da leitura, tais como os métodos de ensino e algumas deficiências escolares. Contudo, o que depreendemos da discussão sobre a incapacidade de ler em crianças escolarizadas, aqui já tratada sob o nome de dislexia, é que, a despeito do significativo aumento nas pesquisas, o tema também permanece em aberto, mais de trinta anos após a publicação da obra de Kanner.

\section{As dificuldades escolares das crianças}

Ao abordar o tema amplo das dificuldades escolares, Ajuriaguerra retomará a consideração de possíveis déficits instrumentais (cognitivos ou orgânicos), incluindo o que chamou "distúrbios de personalidade" em evolução, cujos conflitos poderiam gerar desde uma recusa aberta à escola, caracterizada por comportamentos de oposição, crises de raiva e cólera, ou uma recusa passiva, expressa por uma falta de interesse. Nessa mesma direção causal situa as síndromes de inibição intelectual, nas quais a criança sofre por não poder dedicar-se à atividade intelectual, mesmo que queira, produzindo, como efeito, uma série de comportamentos, associados à atenção e fixação de conhecimentos, que comprometem o aprendizado. A consideração desses distúrbios associados à personalidade não recebem de nosso autor explicações mais aprofundadas. Fica-se, contudo, com a impressão de que a concepção de personalidade de Ajuriaguerra se aproxima da proposta por Kanner, cujo fim seria a adaptação do indivíduo através da integração dos diversos fatores.

Em relação aos problemas associados à aprendizagem e à vida escolar, objeto principal de nossa investigação, o que encontramos no Manual de Ajuriaguerra é, sem dúvida, uma categorização mais ampliada em relação à proposta por Kanner. Embora considere fatores que extrapolam a lógica estritamente organicista, percebemos que Ajuriaguerra se mantém fiel a um modelo funcionalista de análise, caracterizado pela busca de relações funcionais entre os eventos que tende sempre a uma adaptação do indivíduo ao contexto em que se encontra.

É também notável seu esforço em incorporar as diversas contribuições teóricas na análise dos fenômenos em questão; contudo, encontra grande dificuldade em chegar a conclusões definitivas. Preocupa-nos, entretanto, o fato de que, mesmo inconclusivas, essas especulações tenham deixado atrás de si um rastro de hipóteses diagnósticas que, muitas vezes, acabaram por se consolidar.

\section{Conclusão}

As contribuições de Kanner e Ajuriaguerra evidenciam a maneira como, no início do século XX, evolui a abordagem, no campo da 
psiquiatria, das questões relacionadas à criança e, especificamente, das dificuldades de aprendizagem.

A clínica psiquiátrica da criança ganha, assim, novo impulso com a introdução de novas teorias e instrumentos que permitem não só a diferenciação definitiva da clínica do adulto, mas a elaboração de justificativas teóricas mais amplas para as mais diversas questões, incluindo as dificuldades relativas à aprendizagem. Nesse contexto, merecem destaque a utilização da psicometria, através das escalas de Binet e Simon, os trabalhos de inspiração funcionalista e behaviorista e as influências da teoria psicanalítica, com sua revolucionária cont cepção de infância, conhecimentos oriundos das psicologias que contribuem para compor o quadro explicativo sobre as dificuldades de aprendizagem a partir do início do século XX.

Em nossa leitura verificamos, especificamente no campo das questões relativas à aprendizagem, a predominância de duas vertentes de compreensão que se apresentam com mais força e que, ainda hoje, parecem dividir a opinião dos que se dedicam às dificuldades das crianças no campo da educação. A aposta na referência a uma base orgânica, que em última instância poderia esclarecer a razão das dificuldades de aprendizagem das crianças, e, por outro lado, a referência ao que podemos denominar, mais genericamente, de "causalidade psíquica", que refere-se aos conflitos experimentados pelo indivíduo localizados no âmbito de uma organização psíquica relativamente independente do organismo. Embora saibamos que tal posição possa variar na dependência do enfoque teórico utilizado, nas fontes aqui consultadas a abordagem dessa "causalidade psíquica" permaneceu associada a uma concepção eminentemente integradora de personalidade, responsável pela organização de diversas funções, visando à adaptação do indivíduo ao contexto em que se encontra, marcas do enfoque predominantemente funcionalista já mencionado. Nessa vertente, cuja tese repousa num fundamento naturalista, fica excluída toda possibilidade de uma causalidade apoiada nos interesses idiossincráticos dos sujeitos. A lógica funcionalista propõe uma generalização das razões últimas responsáveis pelo que acomete as crianças. Logo, as possibilidades de existirem outras razões que apontem para a diferença em que se constitui cada sujeito ficam anuladas.

Como profissionais ligados ao campo da psicologia e da educação, sabemos hoje que as diversas teorias e instrumentos que se constituíram em elementos fundamentais para que a abordagem das questões relacionadas às crianças conquistasse uma especificidade, 
continuaram sendo objeto de pesquisas que, ao longo dos anos, possibilitaram uma maior precisão de seus fundamentos e teses. Tal esforço possibilitou, inclusive, uma diferenciação mais precisa quanto aos pressupostos epistemológicos dessas diversas correntes.

Perguntamo-nos, entretanto, se tal evolução caminhou na direção da preservação de uma abertura para explicações ainda não inventadas, incluindo a possibilidade de cada sujeito dizer sobre o que lhe acontece, ou se permanecemos na ilusão de uma produção de conhecimento que ignora seus limites.

LEARNING DIFFICULTIES AND PSYCHIATRIC SCIENCE: A CRITICAL READING

\begin{abstract}
This article presents a critical examination of the ways in which learning difficulties were addressed by the psychiatric science when they emerged as a major social problem. Despite the influence of the various theories about children and their development produced in the first half of the 20th century, this article identifies a predominance of the functionalist approach to the identification of the learning disability, a tendency evident in the search for an organic causality or the regarding of a "psychic causality" as an attempt to justify the learning disability. In both situations is evident the silencing of children, who are treated as mere subjects of several scientific speculations.
\end{abstract}

Index terms: learning difficulties; psychiatric science; children.

LASDISCAPACIDADES DE APRENDIZAJE Y LACIENCIA PSIQULÁTRICA: UNA LECTURA CRÍTICA

\title{
RESUMEN
}

En este artículo se presenta un análisis crítico sobre cómo las discapacidades de aprendizaje han sido abordadas por la ciencia psiquiátrica cuando caracterizadas como un problema social. A pesar de la influencia de varias teorias publicadas en la primera mitad del siglo XX sobre la niñezy su desarrollo, este articulo identificó el predominio de un abordaje funcionalista, que se muestra evidente como una búsqueda por una causalidad orgánica o una "causalidad psíquica" en el intento de justificar las discapacidades de aprendiraje. En ambas situaciones se bace evidente el silenciamiento de los niños, tratados como mero objeto de las varias especulaciones científicas.

Palabras clave: discapacidades de aprendiraje; ciencia psiquiátrica; niños.

\section{REFERÊNCIAS}

Ajuriaguerra, J. (1983). Manual de psiquiatria infantil (P. C. Geraldes \& S. R. Pacheco, trads.). São Paulo, SP: Masson.

Ariès, P. (1981). História social da criança e da família (D. Flaksman, trad.). Rio de Janeiro, RJ: LTC.

Bercherie, P. (1989) Os fundamentos da clinica: história e pesquisa do saber psiquiátrico (V. Ribeiro, trad.). Rio de Janeiro, RJ: Jorge Zahar. 
Bercherie, P. (2001) A clínica psiquiátrica da criança: estudo histórico. In O. Cirino, Psicanálise e psiquiatria com crianças: desenvolvimento ou estrutura (pp. 127-144). Belo Horizonte, MG: Autêntica.

Binet, A., \& Simon, T. (1929). Testes para a medida do desenvolvimento da inteligência nas crianças (Lourenço Filho, trad.). São Paulo, SP: Melhoramentos.

Boto, C. (2003). Na revolução francesa, os princípios democráticos da escola pública, laica e gratuita: o relatório Condorcet. Educação e Sociedade, 24 (84), 735-762.

Cirino, O. (2001). Psicanálise e psiquiatria com crianças: desenvolvimento ou estrutura. Belo Horizonte, MG: Autêntica.

Esteve, J. M. (2004). A terceira revolução educacional: a educação na sociedade do conhecimento (C. Antunes, trad.). São Paulo, SP: Moderna.

Ferreira, A. A. L., \& Araujo, S. F. (2009). Da invenção da infância à psicologia do desenvolvimento. Psicologia em Pesquisa, 3 (2), 3-12.

Kanner, L. (1971). Psiquiatría infantil. Buenos Aires, Argentina: Psique.

Santiago, A. L. (2005). A inibiçâo intelectual na psicanálise. Rio de Janeiro, RJ: Jorge Zahar.

Sauret, M-J. (1998). O infantil e a estrutura (S. Sobreira, trad.). São Paulo, SP: Escola Brasileira de Psicanálise.

Sauret, M-J. (2003). A pesquisa clínica em psicanálise. Psicologia USP, 14 (3), 89104. doi: http://dx.doi.org/10.1590/S0103-65642003000300009

\section{NOTAS}

1. A introdução dos diagnósticos de debilidade e imbecilidade representam desdobramentos das formas de idiotia a partir da classificaçáo possibilitada pelo emprego das escalas de inteligência. Dessa forma, os "estados inferiores de inteligência” são classificados.

2. Referimo-nos aqui aos tribunais criados no final do século XIX, na Austrália e nos EUA, para atendimento, em separado, das crianças delinquentes. Instituiçóes que, segundo Kanner (1973), resultaram dos esforços de homens e mulheres de "mentalidade cívica" que entendiam ser prejudicial para o desenvolvimento das crianças o tratamento recebido pela mesma justiça aplicada ao adulto.

3. Nessa primeira geração destacam-se, segundo Paul Bercherie (2001), os trabalhos franceses de Moreau de Tours Filho (1888) e Manhein (1899), o alemão de Emminghaus (1887) e o inglês de Ireland (1899).

4. Estudos sobre o comportamento infantil, conforme o modelo adquirido nas pesquisas realizadas sobre o comportamento animal, com ênfase na relação entre o comportamento e o ambiente.

5. Jean Piaget (1896-1980).

6. No original: "Déjelo, ya va hablar", "Es un niño mimado", "Oye perfectamente", "Es duro de oído", "Es inteligente", "Es débil mental", "Tiene una lengua un tanto gruesa..." "Los nervios lo entorpecen." (Kanner, 1971, p. 531). 
7. O termo dislexia veio substituir nomenclaturas como "cegueira verbal", "afasia visual" ou "alexia", provenientes desses primeiros estudos que apontavam causas orgânicas como responsáveis pela incapacidade de ler.

8. No original: "La personalidad es la organización dinámica, dentro del individuo, de los sistemas psicofísicos que determinan su singular adaptación al ambiente que lo rodea" (Kanner, 1971, p. 107).

9. O termo pulsional é referente a uma força de caráter endógeno dependente, em parte, do "equipamento geral do indivíduo" e remanejada pelas respostas do ambiente. A utilização do termo não deixa de remeter à teoria freudiana; no entanto, sua significação, em função mesmo dos desdobramentos do raciocínio de Ajuriaguerra, permanecerá mais atrelada aos seus componentes biológicos do que psíquicos. Sobre essa questão vale conferir o item "Propósito de certas noções psicanalíticas" (Ajuriaguerra, 1983, p. 33).

marialice@ig.com.br

Alameda dos Madrigais, 312 34.000-000 - Nova Lima - MG - Brasil. 